\title{
Beitrag zur Bakterienökologie einiger Seen des Schwarzwaldes und der Schweiz
}

Eine vergleichende Darstellung unter Anwendung der Direktzählmethode und einer differenzierten Plattenmethode

Von E. Schegg, EAWAG, Dübendorf, und

R. Ruschke, Limnologisches Institut der Universität Freiburg i. Br., Falkau, Schwarzwald 


\section{Einleitung}

Seit langem weiss man, dass die Bakterien als heterotrophe Organismen auf der Seite der Destruktion der wichtigste Faktor im Stoffkreislauf der Seen sind; dennoch ist bisher erst wenig über die Ökologie planktischer Bakterien bekanntgeworden. Babenzien [1], RodHe [2] und Overbeck [3] wiesen in letzter Zeit auf den Mangel an Kenntnis der Ökologie dieser Mikroorganismen hin.

Es gibt wohl verschiedene Gründe dafür, dass die Ökologie der Bakterien, obwohl Schlüsselpunkt zum Verständnis der biologischen Prozesse in den Gewässern schlechthin, zuwenig intensiv erforscht wurde. Die Probleme, die sich jeder ökologischen Forschung stellen, fallen bei der Gewässerbakteriologie infolge der kleinen Dimensionen der Untersuchungsobjekte besonders ins Gewicht. Die apparative Ausrüstung, die das bakteriologische Arbeiten erfordert, konnte bisher nicht von jedem Institut aufgebracht werden, das sich mit Limnologie befasste. Ferner fehlt es heute noch an genügend Kräften, die sich limnobakteriologischer Probleme annehmen.

Die vorliegende Arbeit soll ein Beitrag zur «statischen» Ökologie sein, in welcher aber durch Aufnahme einzelner Profile verschiedener Seen versucht wurde, einen Weg zu finden, der eine Annäherung an die «dynamische» Ökologie ermöglicht, der OVERBECK [3] durch automatische Registrierungseinrichtungen schon weit entgegengekommen ist.

Im ersten, mehr physiologisch orientierten Teil unserer Arbeit (ausgeführt von R. RuschKE) wird aufgezeigt, welchen Einfluss das $\mathrm{pH}$ des Inkubationssubstrats auf die Entwicklung von Keimen ausübt, die Gewässern unterschiedlicher Azidität entstammen.

Durch Variation des Nährboden-pH sollte eine individuelle Anpassung an die Bakterienpopulationen der verschiedenen Seen erreicht werden, die zu Koloniezahlen führt, welche sich weit aus dem Rahmen der mit dem Kochschen Plattengussverfahren $z \mathbf{u}$ erzielenden «Keimzahlen» herausheben. 
Im zweiten Teil der Arbeit (ausgeführt von E. SchEGG) wurde versucht, aus Profilaufnahmen, in welche verschiedene, die Biozönose eines Sees prägende Parameter einbezogen sind, auf die Dynamik des Stoffumsatzes in den untersuchten Gewässern zu schliessen. Die Keimzahlen, die mit der Plattenmethode und durch Direktzählung auf Membranfiltern ermittelt wurden, sollten, ergänzt durch die miterfassten Umweltfaktoren Temperatur, Sauerstoffgehalt, Phytoplanktongehalt und Primärproduktionsrate, einige Rückschlüsse auf die Bedeutung der Bakterien in den Gewässern ermöglichen.

Von der Fragestellung her erschien uns eine nur einmalige Untersuchung verschiedener Seentypen bereits dazu geeignet, Charakteristika dieser Gewässer aufzuzeigen.

1968 wurden folgende Seen, bezüglich deren Orographie auf die zitierten Literaturstellen verwiesen wird, untersucht:

See

Untersuchungsdatum ${ }^{\mathbf{1}}$ )

Vierwaldstättersee

Feldsee

Ursee

Bodensee-Überlingersee

Titisee

Baggersee
LEEMANN [4]

Elster und Motsch [5]

ELSTER [6]

ELSTER und MOTSCH [5]

Elster und Motsch [5]
25. Mai 1968

25. Juni 1968

1. August 1968

17. August 1968

12. September 1968

3. Oktober 1968

\section{Keimzahluntersuchungen nach der Plattenmethode}

Bei Keimzahlbestimmungen nach einer differenzierten Plattenmethode kamen wir zu dem Ergebnis, dass hohe Zahlen immer dann zu erwarten sind, wenn Proben aus relativ sauren Gewässern auf Agarplatten mit niedrigem $\mathrm{pH}$ ausgespatelt werden, sowie wenn Proben aus alkalischerem Milieu auf Platten mit entsprechend höherem Agar-pH aufgebracht werden [7].

Bei der vorliegenden Untersuchung entnahmen wir Proben aus jeweils 5 Tiefenstufen, die zur Bestimmung des Gehaltes an heterotrophen aeroben Keimen auf dem bewährten Moutonagar verspatelt wurden. Wir hofften einen Hinweis auf die horizontale Schichtung bestimmter Bakterienarten oder -populationen innerhalb des Wasserkörpers dadurch zu erhalten, dass die Proben jeweils parallel auf Agarplatten mit verschiedenen $\mathrm{pH}$-Einstellungen bebrütet wurden. Um Bakterienaggregate aufzulösen, mixten wir jede Probe vor der Verarbeitung in einer Menge von etwa $200 \mathrm{ml}$ eine Minute lang mit dem Ultra-Turrax-Handmixstab. Mit 0,05 oder 0,1 $\mathrm{ml}$ dieses gemixten Probenwassers beimpften wir dann die Moutonagarplatten, die auf acht $\mathrm{pH}$ Werte zwischen $\mathrm{pH} \mathrm{5,0}$ und 9,0 eingestellt waren. Für jede $\mathrm{pH}$-Einstellung setzten wir 10 Parallelproben ein, das bedeutet, dass für jede Probe aus einer Tiefenstufe 80

1) Die Untersuchungen wurden mit finanzieller Unterstützung durch die Deutsche Forschungsgemeinschaft und die "Stiftung der Wirtschaft zur Förderung des Gewässerschutzes in der Schweiz 》, am Limnologischen Institut der Universität Freiburg i. Br. in Falkau (Schwarzwald) und am Hydrobiologischen Laboratorium Kastanienbaum der ETH durchgeführt. Den Herren Professoren Dr. H.-J.Elster und Dr. Otto Jaag danken wir herzlich für die bereitwillige Förderung unseres Vorhabens. Zu grossem Dank sind wir Fräulen K. Köhn für die technische Assistenz und Fräulein G. Schulze, Falkau, für das Anfertigen von Zeichnungen verpflichtet. Herrn Dr. Ambühl danken wir für die Durchsicht des Manuskriptes. 
und für die Untersuchung eines Sees in 5 Tiefenstufen 400 Agarplatten ausgewertet wurden. Spätestens 3,5 h nach der Entnahme aus dem See waren alle Proben verspatelt. Bis zur Verarbeitung beliessen wir sie, noch ungemixt, im Kühlschrank. Die Platten wurden bei $22^{\circ} \mathrm{C} 5$ Tage lang bebrütet. Eine ausführliche Beschreibung der Probenbehandlung und der Agarpräparation findet sich bei RuschkE und KöHN [7].

\subsection{Vierwaldstättersee}

Probenahme am 24./25. Mai 1968 in Seemitte zwischen Kehrsiten und dem Hydrobiologischen Laboratorium der ETH, Kastanienbaum.

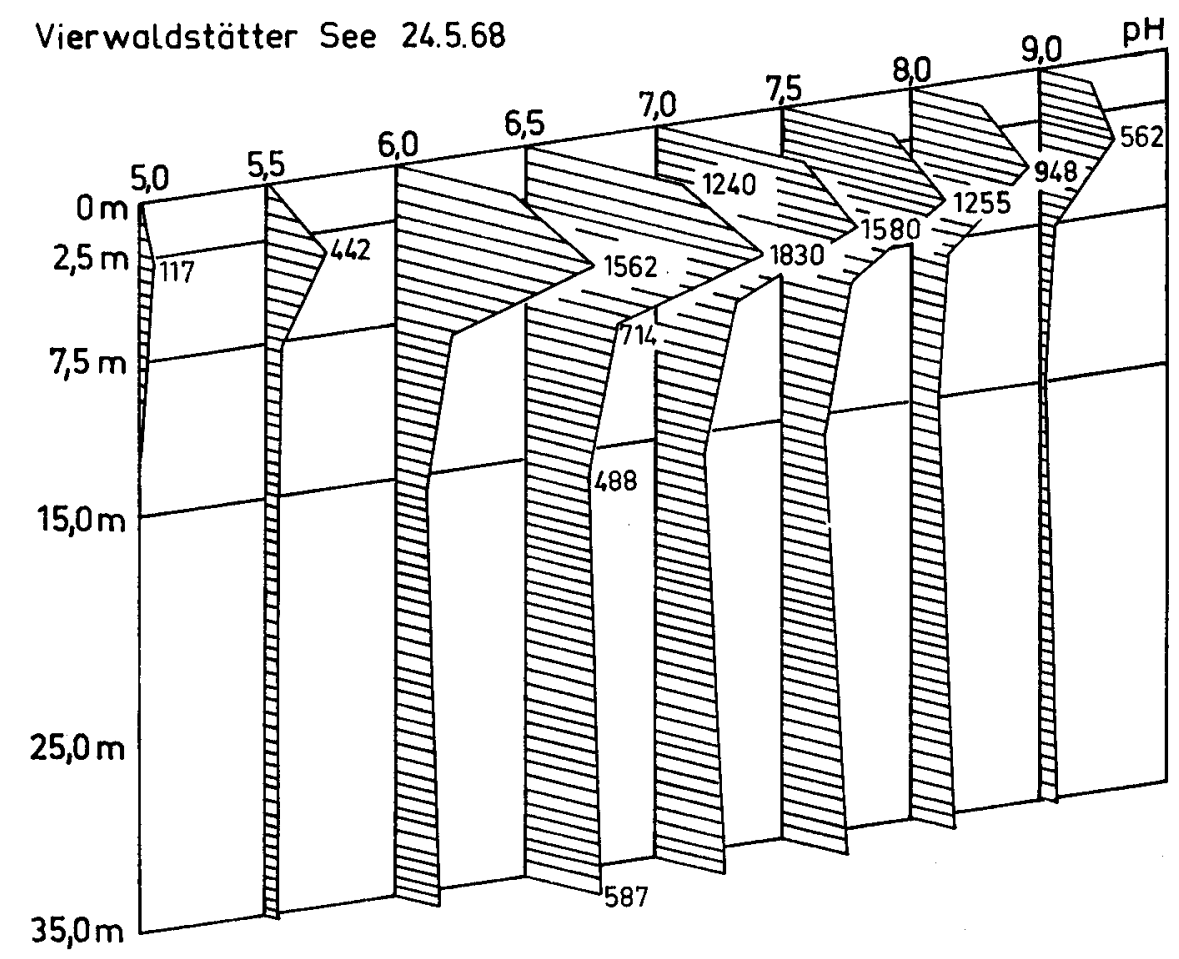

Abb. 1. Koloniezahl pro ml Probenwasser aus verschiedenen Tiefenstufen in Abhängigkeit von der pH-Einstellung des Agars.

Wie Abb. 1 zeigt, verliefen für alle pH-Stufen des Agars die Kurven prinzipiell gleich: steiler Anstieg der Koloniezahlen von der Oberfläche ausgehend bis 2,5 m Tiefe, dann rasches und bis $15 \mathrm{~m}$ Tiefe langsameres Zurückgehen. In $35 \mathrm{~m}$ Tiefe etwa $2 \mathrm{~m}$ über Grund - stiegen die Keimzahlen wiederum leicht an.

Maximale Koloniezahlen erbrachten also die Proben aus der trophogenen Schicht. Mit dieser sehr wichtigen Feststellung werden wir uns auch noch im zweiten Teil auseinandersetzen.

Der aktuelle $\mathrm{pH}$-Wert des Sees zur Zeit unserer Untersuchung betrug 8,4 in $2,5 \mathrm{~m}$ Tiefe (die Werte liegen im Vierwaldstättersee fast immer um $\mathrm{pH} 8$ ), weshalb wir mit 
Feldsee 25.6.68

$22 \mathrm{~m}$

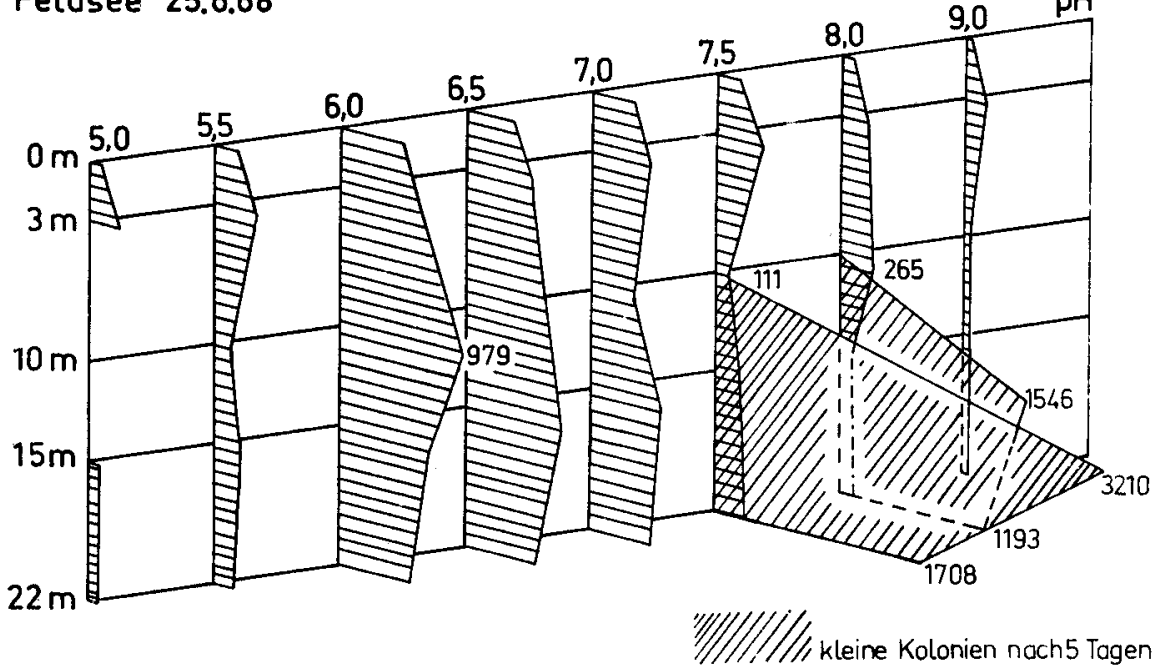

Abb.2. Probenahme am 25. Juni 1968, Seemitte (Darstellung analog Abb.1).

einem Koloniemaximum auf Agarplatten von $\mathrm{pH}$ 7,0 bis 8,0 rechneten. Das Koloniemaximum trat jedoch überraschend bei $\mathrm{pH}$ 6,5 auf, und zwar bei den Proben aus allen Tiefenstufen. Vorläufig können wir für diesen Befund keine Erklärung geben.

\subsection{Feldsee}

Der Feldsee wies in den geprüften Tiefenstufen folgende $\mathrm{pH}-W e r t e$ auf : Oberfläche

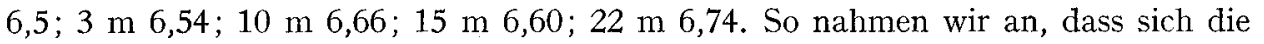
meisten Kolonien auf den Agarplatten mit niedrigem $\mathrm{pH}$ entwickeln würden.

Tatsächlich fand sich das Maximum jener Kolonien, die so ausgebildet waren, wie wir es auf Moutonagar erwarten konnten, aus allen Tiefenstufen auf Agar von pH 6,0. Die Probe aus $3 \mathrm{~m}$ Tiefe enthielt mehr Keime als jene von der Seeoberfläche. Für die Stufen unterhalb $3 \mathrm{~m}$ Tiefe verlaufen die Koloniezahlkurven für die verschiedenen pH-Einstellungen des Agars nicht mehr einheitlich. Das Koloniemaximum fand sich auf $\mathrm{pH}$ 6,0-Agar aus $10 \mathrm{~m}$ Tiefe, auf Platten von $\mathrm{pH} \mathrm{6,5}$ und 7,0 aus $15 \mathrm{~m}$ Tiefe, während auf den Platten mit anderer $\mathrm{pH}$-Einstellung ein Koloniezahlmaximum aus der 3-m-Probe ermittelt wurde.

Unerwartet erschienen nach einer Bebrütungszeit von 5 Tagen in sehr grosser Zahl winzig kleine, weisse Kolonien sehr kleiner, unbeweglicher Stäbchenbakterien auf den Platten von $\mathrm{pH} 7,5$ und 8,0, die mit Proben aus 15 und $22 \mathrm{~m}$ Tiefe beimpft worden waren.

Diese Kolonien unterschieden sich wegen ihres zeitlich späteren Auftretens und der geringen Grösse eindeutig von den übrigen inzwischen ausgewachsenen Bakterienkolonien. Der Zahlenwert dieser kleinen Kolonien ist in Abb. 2 als Schraffur von rechts oben nach links unten eingezeichnet.

Eine Kontrolluntersuchung sechs Tage nach unserer Probenahme erbrachte den gleichen merkwürdigen Befund. Wir wissen nicht, um welche Keime es sich hier 
handelte, nehmen aber an, dass sie nicht autochthon waren, wenngleich eine Einschwemmung durch den Hauptzufluss längere Zeit vor der Probenahme erfolgt sein musste. Der Feldseezufluss schichtete sich bei einer Temperatur von $12^{\circ} \mathrm{C}$ zu dieser Zeit bei 4-6 $\mathrm{m}$ Wassertiefe ein.

Diese Erscheinung lässt an die von JANNASCH [8] beschriebenen "waiting cells" denken, Keimformen, die in physiologisch inaktivem Zustand längere Zeit überdauern können und erst bei entsprechend günstigen Umweltsbedingungen ein lebhaftes Vermehrungswachstum zeigen.

\section{3 Überlingersee}

In Abb. 3 verlaufen die Kurven bei den Agar-pH-Stufen von 6,0-9,0 praktisch gleich:

Anstieg zu einem Maximum bei der Probe aus 2,5 m Tiefe, dann meist geringere Keimzahlen aus dem Wasser aus $9 \mathrm{~m}$ Tiefe. Ähnlich sehen die Kurven für die pHStufen 5,0 und 5,5 aus; die Koloniezahlen betragen hier jedoch nur etwa $10 \%$ der bei den höheren $\mathrm{pH}$-Einstellungen erhaltenen Werte.

Das Bodenseewasser wies zur Zeit der Probeentnahme in den untersuchten Tiefen

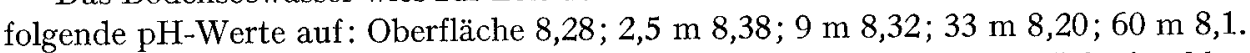
Das pH der Nähragarplatten, die aus allen Tiefenstufen die höchsten Koloniezahlen erbrachten, betrug 7,0. Aber auch auf Agar, der auf die $\mathrm{pH}$-Werte 7,5 und 8,0 eingestellt war, wurden noch rund 85\% der Anzahl der auf den $\mathrm{pH} 7,0$-Platten gezählten Kolonien gefunden.

Die Probe aus $60 \mathrm{~m}$ Tiefe wurde der gerade in Betrieb stehenden Förderleitung des Seepumpwerkes Sipplingen entnommen. Im Hinblick auf die Trinkwasserversorgung ist es bemerkenswert, dass aus dieser Probe $87 \%$ der Anzahl der aus der Oberflächen-

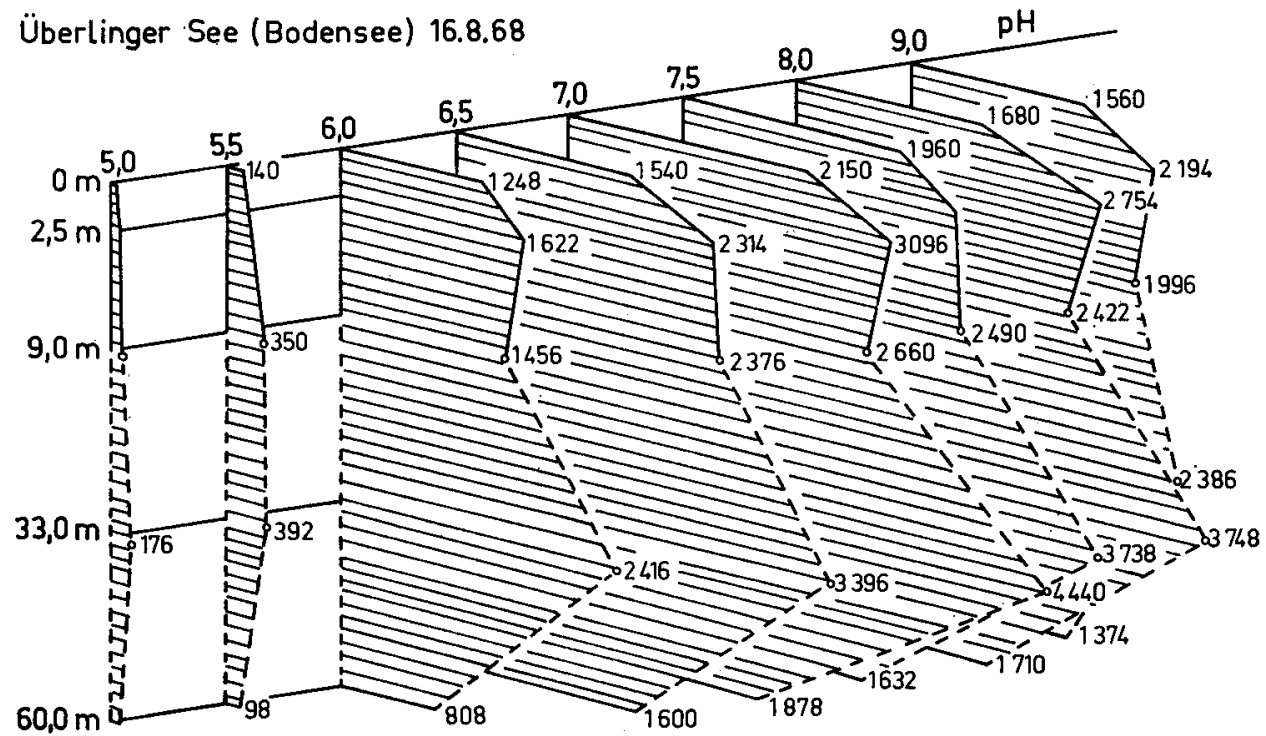

Abb. 3. Probenahme am 16. August 1968, $300 \mathrm{~m}$ vor dem Seepumpwerk Süssenmühle (Darstellung analog Abb.1). 
probe ausgewachsenen Kolonien und etwa 42\% der Anzahl der aus $33 \mathrm{~m}$ Tiefe angezüchteten Kolonien festgestellt wurden.

Die hier ermittelten Keimzahlen liegen um mehr als eine Zehnerpotenz höher als vergleichbare Werte aus unseren Untersuchungen in den Jahren 1960-1962 [9], was sicher auf die inzwischen verbesserte Untersuchungstechnik zurïckzuführen ist. Durch die bakteriologische Prüfung des Vertikalprofils liess sich klar belegen, dass das aus $60 \mathrm{~m}$ zur Trinkwasserversorgung entnommene Wasser Keimzahlen aufweisen kann, die jenen aus der Oberflächenschicht durchaus nahekommen. Es ist falsch, anzunehmen, das Wasser aus tieferen Seeschichten sei keimärmer als jenes aus Oberflächennähe, was sich auch mit dem ausgeprägten Keimzahlmaximum in $33 \mathrm{~m}$ Tiefe belegen lässt.

\subsection{Titisee}

Die Kurven für pH 5,0, 8,0 und 9,0 verlaufen etwa in gleicher Weise: Koloniemaximum aus der 2,5-m-Probe, dann mit zunehmender Wassertiefe stetige Verringerung der Koloniezahl. Ähnlich sieht die $\mathrm{pH}-5,5-\mathrm{Kurve}$ aus, die jedoch ein Koloniemaximum aus $6 \mathrm{~m}$ Wassertiefe aufweist. Zwei Koloniemaxima zeigen die pH 6,5-, 7,0- und 7,5-Kurven, nämlich für die Proben aus 2,5 und $9 \mathrm{~m}$ Wassertiefe. Die pH-6,0-Kurve weist dagegen Koloniemaxima für die 2,5-m-Probe und die Probe aus $15 \mathrm{~m}$ Tiefe auf. Sowohl die pH 6,0- als auch die pH-6,5-Kurve zeigen in $15 \mathrm{~m}$ Wassertiefe einen fast ebenso hohen Keimgehalt an wie für die Seeoberfläche. Auf Agar, der auf $\mathrm{pH}$ 6,5 eingestellt war, wuchsen die meisten Kolonien aus. Die pH-Werte des

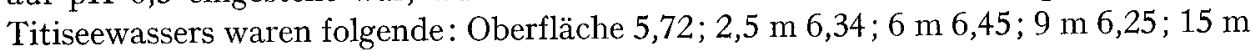
6,$17 ; 32 \mathrm{~m} 6,38$.

Als spezielle physiologische Gruppe wurde der Gehalt an Sporocytophaga cauliformis auf denselben Agarplatten ermittelt, die der Keimzählung (Abb. 4) dienten. Sporocytophaga cauliformis ist eine Myxobakterienart mit ausgeprägten Fähigkeiten

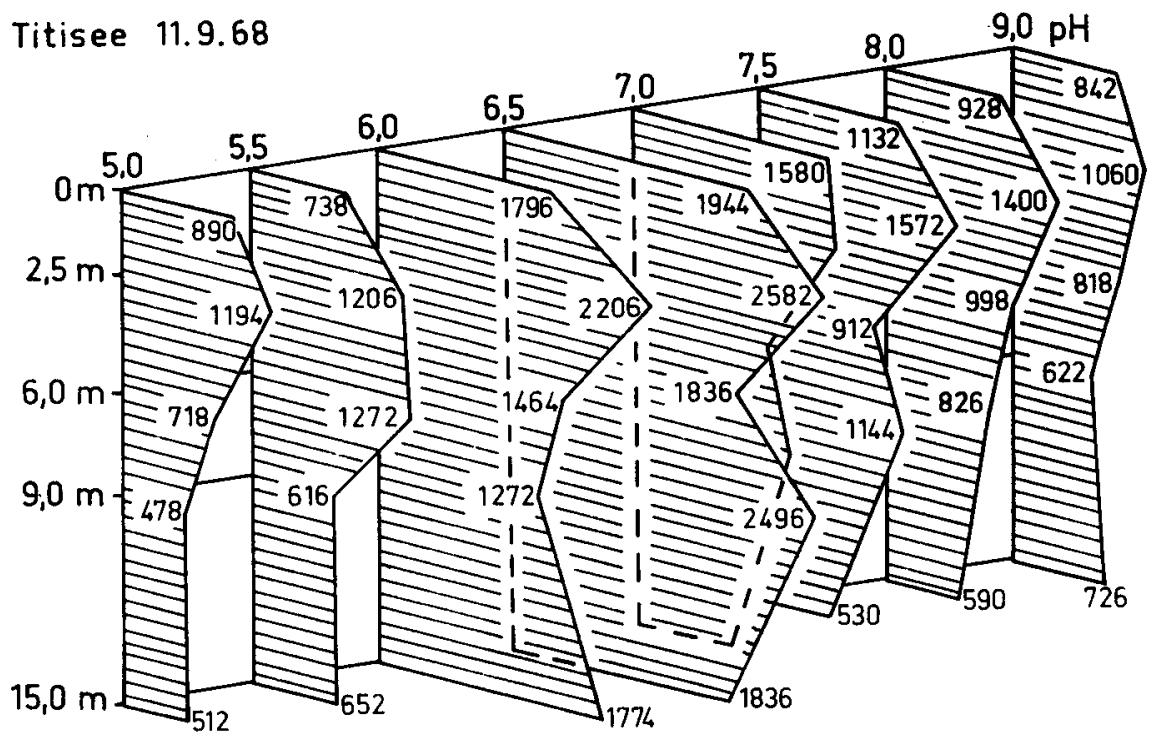

Abb.4. Probenahme am 11. September 1968 in Seemitte vor dem Schwimmsportheim. 


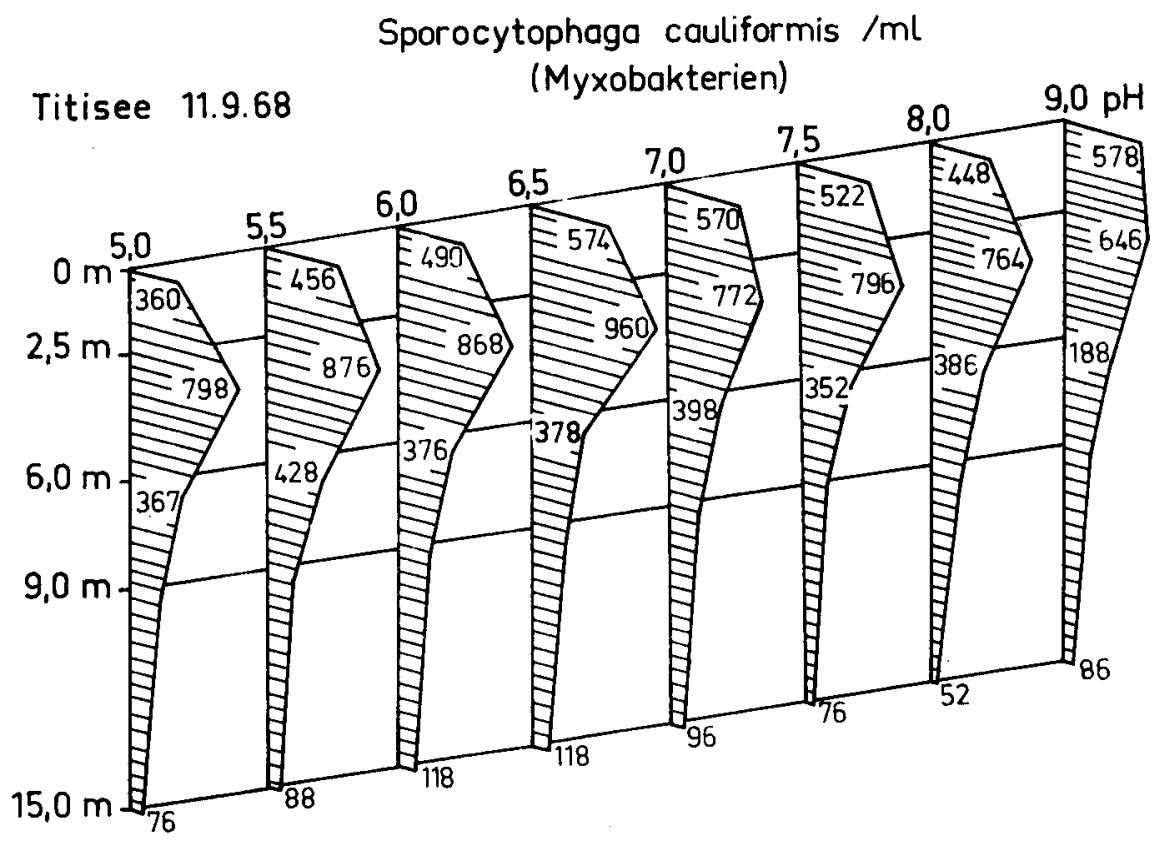

Abb. 5.

zur Remineralisierung organischen Materials [10]. Dem Verhältnis der vorgefundenen Stämme vom Typ I und II dieser Keime wird Bedeutung für die Anzeige des Trophiegrades des betreffenden Gewässers beigemessen [11]. Im Feldsee fanden wir 1965 unter der Eisdecke 50 Sporocytophaga cauliformis pro ml, bei der vorliegenden Untersuchung waren es im Titisee in 2,5 m Tiefe 960 pro ml, was rund einem Drittel der Anzahl der insgesamt auf unserem Nährboden angezüchteten Keime entspricht.

Unseres Wissens wurden Wassermyxobakterien bisher aus keinem Gewässer in so hoher Dichte isoliert. Da in Bodenseeproben und selbst aus der stark fäkal verschmutzten Haslach gegenüber dem schwach eutrophierten Titisee [12] nur ein relativ geringer Gehalt an Sporocytophaga cauliformis ermittelt werden konnte, bleibt die Frage nach der Herkunft dieser Keime im Titisee zu beantworten. Auf jeden Fall müsste geprüft werden, ob diese Bakterien aus der biologischen Kläranlage im Bärental in den Titisee eingeschwemmt werden.

Schon früher wiesen wir an wenigen Stämmen nach, dass Sporocytophaga cauliformis auf Agarplatten im Bereich zwischen pH 5,5 und 8,8 fast gleich gut wachsen kann [10]. Hierfür ist nun das überaus gleichmässige Wachstum auf Moutonagar bei $\mathrm{pH}$ 5,0 bis 9,0 eine eindeutige Bestätigung.

Allein nach dem Plattenverfahren erfolgte die Keimzahlbestimmung aus dem Ursee (Hochschwarzwald) [6] und aus einem Baggersee in der Rheinebene, der relativ alkalisches Wasser aufweist.

\subsection{Ursee}

Nach fünf Bebrütungstagen liessen sich zu unserer Überraschung eine ganze Anzahl kleiner, schwach grüngefärbter Kolonien auf unserem Agar erkennen, die sich 


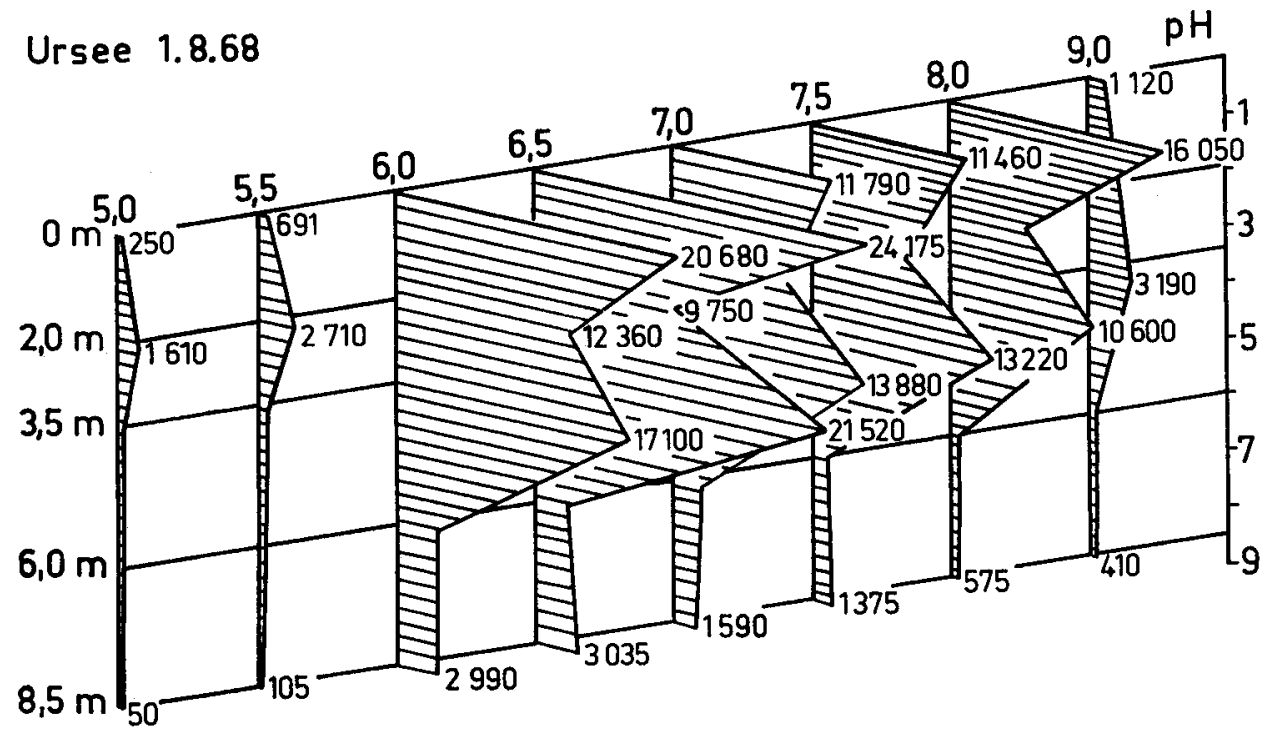

Abb.6. Probenahme am 1. August 1968, Seemitte.

bei mikroskopischer Betrachtung als Chlorellen erwiesen. Der Anteil dieser hauptsächlich aus den Proben bis 3,5 m Tiefe ausgewachsenen Chlorellakolonien war stark $\mathrm{pH}$-abhängig: $86 \%$ der bei $\mathrm{pH} 5,0$ insgesamt ausgewachsenen Kolonien wurden von Chlorellen gebildet; $69 \%$ waren es noch bei $\mathrm{pH} 5$,5, während bei $\mathrm{pH} 6,0$ und allen höheren pH-Werten der Anteil der Chlorellen an der gesamten Koloniezahl 10\% nicht mehr überstieg. War eine Chlorellakolonie beim Agar-pH 5,0 nach fünf Bebrütungstagen aus etwa 200 Zellen zusammengesetzt, so verringerte sich die Zellzahl dieser Kolonien mit steigendem pH ständig; so betrug sie bei pH 7,0 noch 4-8.

Bei keiner unserer bisher durchgeführten bakteriologischen Wasseruntersuchungen, zu welchen Moutonagar eingesetzt wurde, konnte jemals Algenwachstum direkt aus der auf dem Agar verspatelten Probe festgestellt werden. Nach vorliegendem Ergebnis ist es aber durchaus zu empfehlen, die bei einer bakteriologischen Wasseruntersuchung auf den Agarplatten angegangenen Kolonien gelegentlich mikroskopisch durchzumustern (16er Objektiv), um sicherzugehen, dass tatsächlich nur Bakterienkolonien ausgezählt wurden.

In die Gesamtkoloniezahl (Abb. 6) sind die Chlorellakolonien mit einbezogen. Maximal 24000 Kolonien pro $\mathrm{ml}$, davon rund 23000 Bakterienkolonien, bedeuten eine ausgesprochen hohe Keimdichte im Wasser der Seeoberfläche. Ein Kolonieminimum aus der 2-m-Probe wurde von einem Koloniemaximum aus der Probe aus 3,5 m Wassertiefe abgelöst, das wiederum ähnlich hohe Bakterienzahlen erbrachte, wie sie in der Oberflächenprobe ermittelt wurden. Die Keimdichte war im Wasser der Seeoberfläche rund zehnmal höher als in den tieferen Schichten ab $6 \mathrm{~m}$. Die meisten Kolonien zählten wir auf den auf pH 6,5 eingestellten Agarplatten, etwas geringere Werte erbrachten die pH 6,0-Platten. Zur Zeit der Probenahme wies der Ursee in den

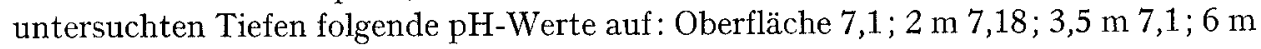
6,$6 ; 8,5 \mathrm{~m} 6,5$. 


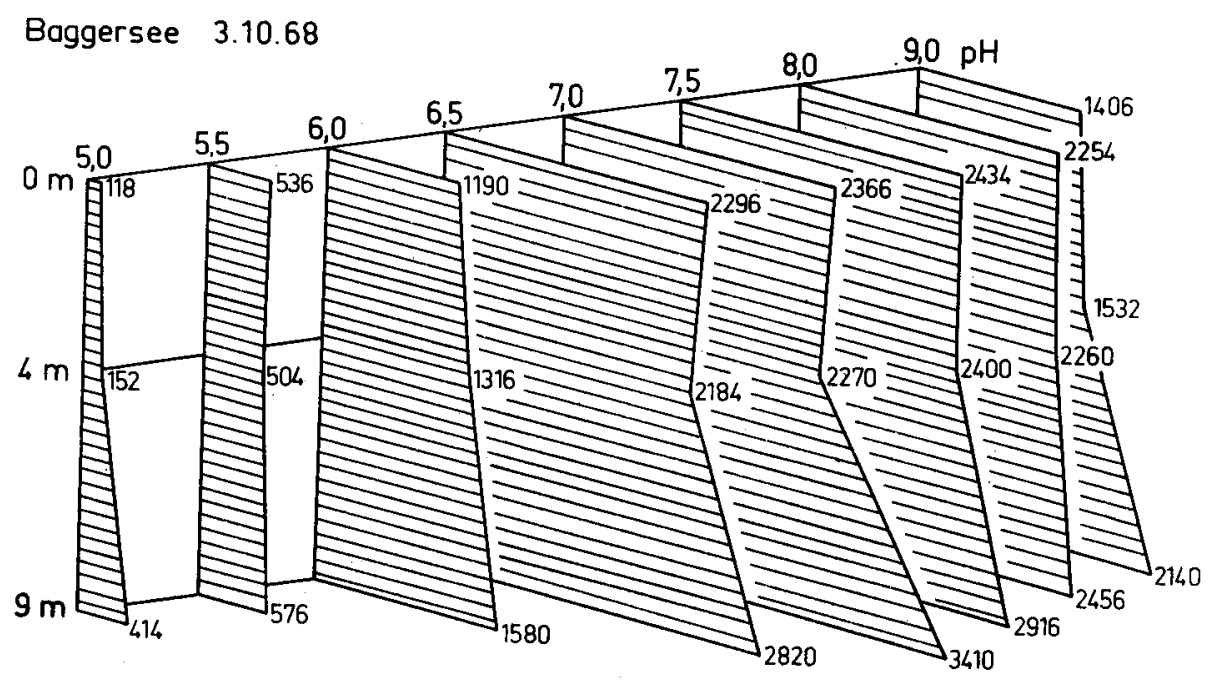

Abb. 7. Probenahme am 3. Oktober 1968 aus dem $14 \mathrm{~m}$ tiefen See.

\subsection{Baggersee bei Forchheim am Kaiserstuhl}

Obwohl die Werte für Agar, der auf ein $\mathrm{pH}$ unter 6,5 eingestellt war, weit hinter jenen für Agar mit höherem $\mathrm{pH}$ zurückblieben, verlaufen alle Kurven in etwa gleicher Weise. Bei allen pH-Einstellungen des Agars wurden aus $9 \mathrm{~m}$ Tiefe die meisten Bakterien angezüchtet. Maximale Koloniezahlen erbrachten die Platten mit pH 7,0 und 7,5. Zur Zeit der Probenahme wurde an der Seeoberfläche ein pH von 7,07 gemessen. Die Temperatur betrug an der Oberfläche $17,8^{\circ} \mathrm{C}$; sie nahm bis $5 \mathrm{~m}$ Tiefe stetig ab und blieb zwischen $5 \mathrm{~m}$ und $14 \mathrm{~m}$ Tiefe konstant bei $17,1^{\circ} \mathrm{C}$ stehen.

\subsection{Diskussion}

Maxima und Minima in der vertikalen Keimverteilung, die sich auf Agarplatten, deren $\mathrm{pH}$-Einstellung nur um $0,5 \mathrm{pH}$-Einheiten voneinander verschieden war, ablesen liessen, zeigen, dass die Masse der Bakterien in vertikal aufeinanderfolgenden Stratifikationen oft völlig anders geartete physiologische Ansprüche stellt. Das bedeutet, dass es sich um Schichtungen von artverschiedenen Bakterien handelt, die allein schon durch die Variation des $\mathrm{pH}$ des «Keimzählagars» selektiert werden können (vgl. Abb. 2, 4, 5).

Die Kurvenpunkte bei der nächsten Abb. 8a-f entstanden durch Addition der Koloniezahlen des gesamten Vertikalprofils, entsprechend den verschiedenen $\mathrm{pH}$ Einstellungen des Agars (= Abszisse). Der hierbei erhaltenen höchsten Keimzahl massen wir den Wert $100 \%$ zu (= Ordinate) und setzten alle übrigen Koloniezahlen in ein entsprechendes Verhältnis. Es lässt sich nun aus dem Flächenanteil, den eine Kurve über der Abszisse umschliesst, erkennen, welcher $\mathrm{pH}$-Bereich des Nähragars den höchsten Kolonieertrag brachte, bzw. ob mehr Keime im alkalischen oder sauren Milieu zu Kolonien auswuchsen. 


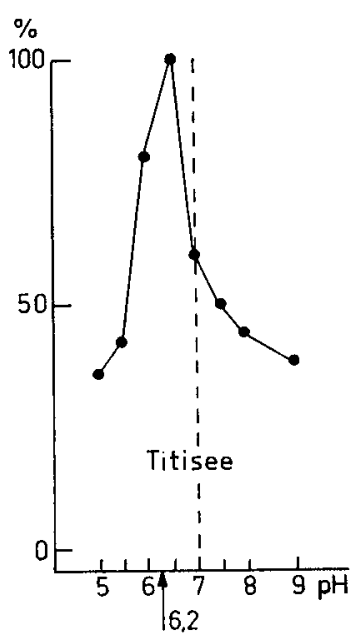

a

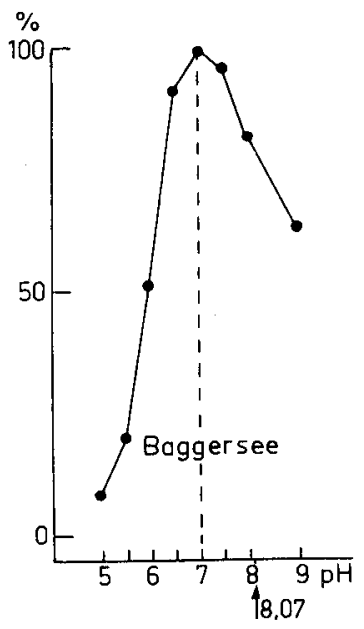

d

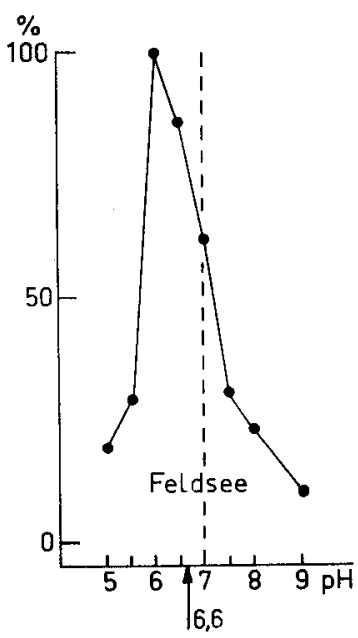

b

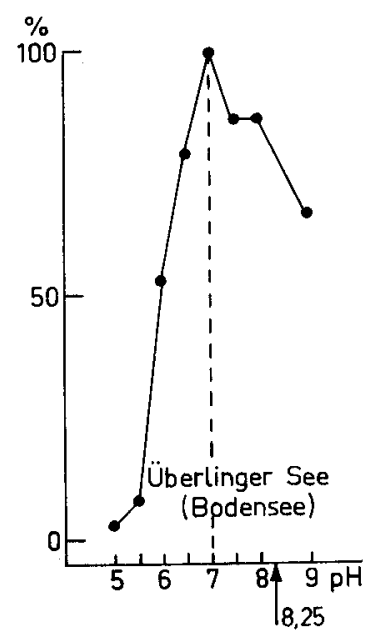

e

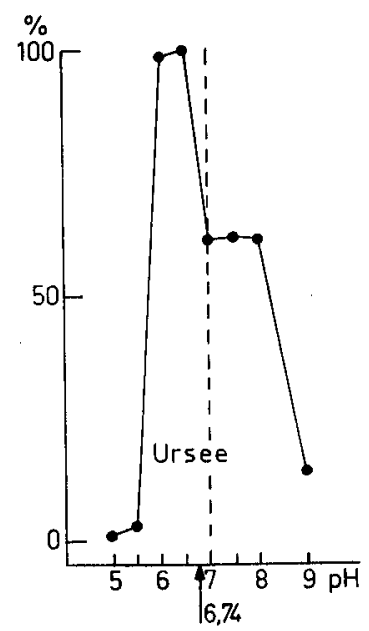

C

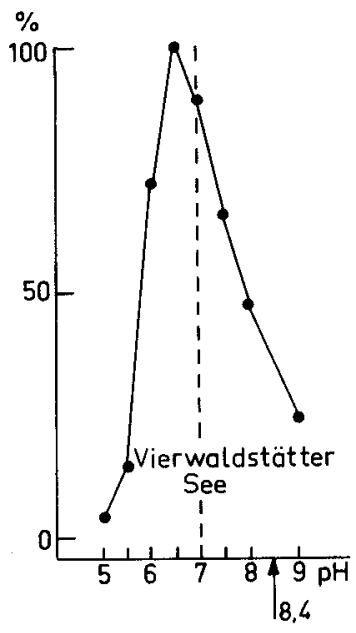

f

Abb. 8. Zusammenfassung der Untersuchungen mit Variation des Nährboden pH.

Das pH des Seewassers, das sich als Durchschnitt aus den Werten der verschiedenen Tiefenproben ergab, ist mit einem Pfeil auf der Abszisse angezeigt.

Mit Ausnahme der Probeuntersuchung des Vierwaldstättersees bestätigen die gewonnenen Ergebnisse unsere Auffassung, dass Koloniemaxima auf Agar mit niedrigem $\mathrm{pH}$ gefunden werden, wenn die Proben aus relativ sauren Gewässern stammen, und dass umgekehrt auf Agar mit hohem $\mathrm{pH}$ Koloniemaxima aus alkalischeren Gewässern erwartet werden können.

Es bleibt zu klären, ob allein das $\mathrm{pH}$ der verschiedenen Gewässer von vorneherein eine von See zu See verschiedene Bakterienflora bedingt, und in welchem Umfang 
eine Adaptation gleichartiger Bakterienpopulationen an unterschiedliche $\mathrm{pH}$-Werte der Seen erfolgen kann.

Bei biologischen Untersuchungen ist es fast immer unmöglich, alle Parameter zu berücksichtigen, die den Ablauf einer Entwicklung beeinflussen. So muss man sich, wie gerade hier bei der Analyse des Stoffkreislaufes eines Sees, damit behelfen, dass man statische Zustandsbilder in geeigneter Form zusammensetzt und aus diesem Mosaik auf die dynamischen Vorgänge schliesst. Nicht selten bleibt jedoch die Zahl der zur Verfügung stehenden Einzeluntersuchungen so klein, dass die Extrapolation der Ergebnisse auf das tatsächliche Geschehen recht schwierig werden kann. Das gilt in besonderem Masse für bakteriologische Gewässeruntersuchungen, die wegen des relativ hohen technischen Aufwandes meist nur in kleinen Serien durchgeführt werden.

Wie problematisch eine nicht durch Parallelansätze gesicherte Keimzahlbestimmung sein kann, zeigte der folgende kleine Versuch:

Am 4. Oktober 1968 entnahmen wir aus dem Titisee, gleichzeitig an zwei 1,5 m auseinanderliegenden Stellen, Proben aus $10 \mathrm{~cm}$ Wassertiefe. Es sollte festgestellt werden, mit welcher Streuung der Koloniezahlen auch dann zu rechnen ist, wenn die Proben derselben Horizontalschicht entstammen.

Beide Proben wurden wieder in der vorgenannten Weise auf je 80 Agarplatten, die auf verschiedene $\mathrm{pH}$-Werte eingestellt waren, verspatelt und 5 Tage bei $22^{\circ} \mathrm{C}$ bebrütet.

Wie aus Abb. 9 ersichtlich ist, unterscheiden sich die beiden Proben sowohl in der Bakteriendichte als auch in der Zusammensetzung voneinander. Im Bereich der höchsten Keimzahlen, auf Agar von $\mathrm{pH}$ 6,5-7,5, betrugen diese aus Probe 2 nur rund $80 \%$ derjenigen aus Probe 1, während mit zunehmend saurer bzw. alkalischer Agar-

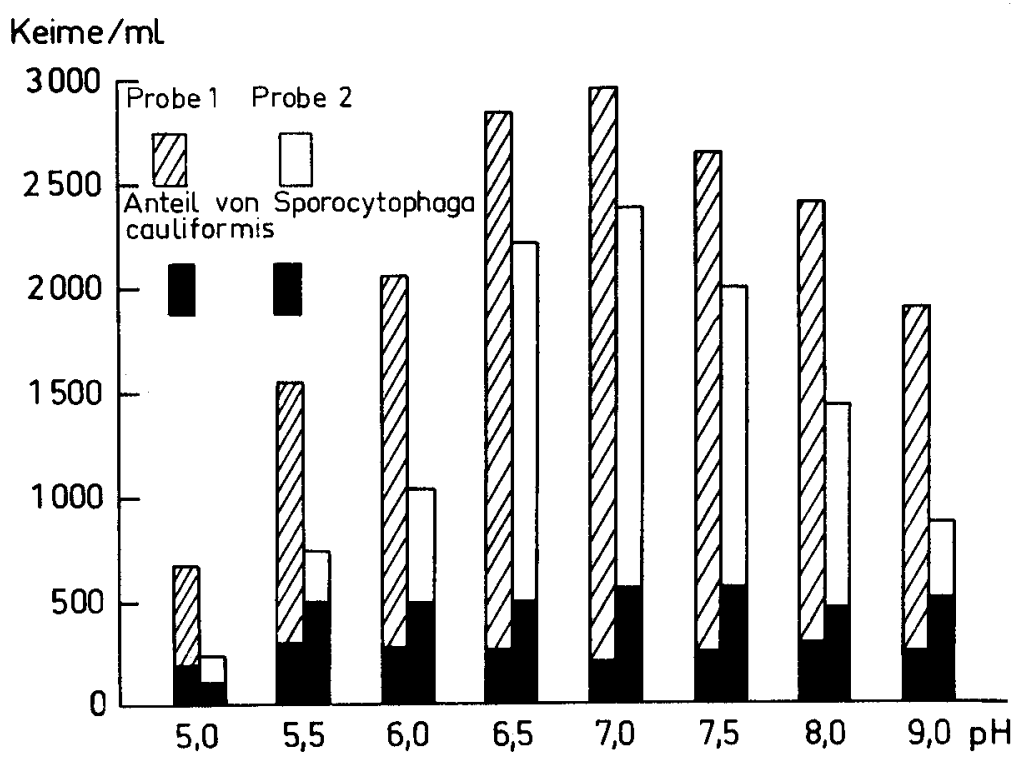

Abb.9. Parallelproben aus dem Titisee am 4. Oktober 1968. 
einstellung die entsprechenden Werte bis auf weniger als 50\% zurückgingen. Die Anzahl der Sporocytophaga-cauliformis-Kolonien war bei Probe 2, also der Probe mit niedrigerer Gesamtkoloniezahl, im ganzen geprüften $\mathrm{pH}-$ Bereich rund doppelt so hoch wie jene aus Probe $1^{1}$ ).

niedrigerer Gesamtkoloniezahl, ausgenommen auf den pH-5,0-Platten, im ganzen geprïften $\mathrm{pH}-$ Bereich rund doppelt so hoch wie jene aus Probe 1.

Das Beispiel zeigt, welch enge Grenzen einer Auswertung der bakteriologischen Ergebnisse gesetzt sind. Wir sind uns dieser Fehlerquellen bewusst, sehen aber vorläufig keine Möglichkeit, die Profilaufnahme in die statistisch einigermassen gesicherte dritte Dimension auszudehnen, weil dieser technische Aufwand schon aus zeitlichen Gründen kaum bewältigt werden könnte.

Trotz dieser bekannten Unzulänglichkeiten soll im nächsten Teil versucht werden, eine Interpretation unserer Ergebnisse auf die Ökologie der untersuchten Seen zu finden.

\section{3. Ökologische Beziehungen}

Gleichzeitig und streng parallel zu den vorgängig beschriebenen Untersuchungen wurden weitere Erhebungen durchgeführt, die vor allem auf die Ökologie abzielten.

Bei der Untersuchung der Bakterien in ihrem "Zuhause» stehen sich immer die beiden Grundbegriffe "Organismus" und "Substrat» gegenüber. Die Bakterien sind als heterotrophe Organismen auf die vom Phytoplankton gebildete organische Substanz angewiesen. Das Substrat, das die Grundlage zur Ausbildung der Bakterienpopulation sowohl in qualitativer als auch in quantitativer Hinsicht bildet, ist wesentlich bestimmt durch die Produktion und die aus dieser resultierenden autolysierten und exkretierten organischen Substanz. Wie schon früher gezeigt wurde [13], ist dieser Zusammenhang recht eng.

Zum Verständnis der geschilderten Beziehungen ist es wesentlich, nicht nur die Seite der Produktion, sondern auch den heterotrophen Abbau, der mit der Bildung bakterieller Biomasse einhergeht, zu kennen. KusNEzow [14] stellte im Rybinskstausee fest, dass die Produktion an Biomasse der heterotrophen Bakterien den Wert der durch die Photosynthese gebildeten Phytoplanktonbiomasse übertraf.

Vollenwerder [15] betont die Wichtigkeit der Erweiterung des Produktionskonzepts des Eutrophierungsproblems im Sinne des von OHLE [16] eingeführten Konzepts der Bioaktivität. Hieraus folgt, dass die Erforschung des Anteils, den die Bakterien am Stoffumsatz in unseren Seen haben, zu einem wichtigen Teilgebiet der Limnologie geworden ist.

Welches sind nun die Möglichkeiten, diesem komplexen System näherzukommen?

Sobald auf die Dynamik des Stoffumsatzes, d.h. auf die ökologische Stellung der Bakterien abgezielt wird, müssen die wichtigsten physikalischen, chemischen und planktologischen Daten als integrierender Bestandteil der Untersuchung betrachtet werden.

Verglichen wurden die Biomasse des Phytoplanktons und dessen Primärproduktion mit den Bakterienzahlen nach der Membranfilter- und nach der Plattenmethode (s. S.3).

1) Die statistische Auswertung [F-Test] der 10 Einzelwerte [Parallelplatten] ergab, dass es sich bei den Proben 1 und 2 um verschiedene Verteilungen handelt. 
Zur weiteren Charkaterisierung wurden die Temperatur und die aktuelle Sauerstoffsättigung berücksichtigt.

Damit sind wesentliche Komponenten dieses aus Substrat und Organismen aufgebauten Ökosystems erfasst worden. Aus arbeitstechnischen Gründen musste auf die Untersuchung des Zooplanktons und dessen Futterbeziehung [17] zu den Bakterien verzichtet werden.

Im folgenden soll anhand von vier Profilen gezeigt werden, welche Schlüsse aus einer solchen an sich statischen Momentaufnahme auf die Dynamik gezogen werden können. Zur klaren Abgrenzung muss vorausgeschickt werden, dass es sich dabei hauptsächlich um Befunde aus dem Epi- und Metalimnion handeln muss, da im Hypolimnion namentlich in stärker eutrophierten Seen prinzipiell andere Bedingungen vorherrschen [28].

\subsection{Methodik}

1. Die Wasserproben wurden mit einer Sterilschöpfflasche (ScHEGG, in Vorbereitung) unter Stickstoffatmosphäre gewonnen.

2. Die Temperatur wurde mittels des «Oxitesters» nach AMBÜHL [18] gemessen.

3. Der Sauerstoffgehalt wurde nach der Winklermethode bestimmt.

4. Das Phytoplankton wurde im Umkehrmikroskop nach UTERmöHL [19] ausgezählt und die Biomasse aus Volumenmessungen und Literaturangaben [20] berechnet.

5. Zur Messung der Photosyntheseaktivität des Phytoplanktons wurde die $\mathrm{C}^{14}$ Methode nach SteEmanN-NiELSEN [21] verwendet.

6. Das Wachstum der heterotrophen Keime wurde nach der auf S. 3 beschriebenen Methode bestimmt, wobei immer die Maximalkurve ausgewertet wurde.

7. Den Auszählresultaten auf Membranfiltern liegt die Methode nach Razumow (aus Kusnezow [22]) zugrunde. Das zu untersuchende Wasser wurde in weniger als einer Stunde aufgearbeitet.

$10 \mathrm{ml}$ Probewasser wurden durch ein Filter MF30 mit 0,22 $\mu$ Porenweite (Membranfiltergesellschaft Göttingen) filtıiert. Als Filtrationsapparatur hat sich das Mikrofiltrationsgerät von Millipore mit einer durchschnittlichen Filtrationsfläche von $2,433 \mathrm{~cm}^{2}$ bewährt. Als Färbemittel diente eine Lösung von 3\% Erythrosin in 5\%iger Phenollösung; dabei wurden die Filter mit Schichtseite nach oben auf ein getränktes Filterpapier gelegt.

Die Filter wurden nach einer Färbezeit von 12 Stunden auf einem feuchten Filterpapier entfärbt, anschliessend getrocknet und auf fettfreien Objektträgern in Immersionsöl (Zeiss, $n_{D}$ 1,515) eingebettet. Das Eindringen des Öls in die Filterhohlräume bewirkt eine vollständige Aufhellung, so dass das durchsichtige Präparat im Phasenkontrast ausgezählt werden kann.

Die Kleinheit des Zellen; bedingt durch das suboptimale Milieu, verlangt, dass bei starken Vergrösserungen gearbeitet wird [10×100]. Dabei leuchten gefärbte Partikeln auf dem schwach rötlichen Untergrund grün auf und behalten diesen Farbeffekt, auch wenn mit der Mikrometerschraube die Bildebene leicht verschoben wird. Voraussetzung für gute Bildqualitäten ist die fast vollständige Entfärbung des Untergrundes. Das genaue Erkennen der Begrenzung der Partikeln ist das wichtigste Kriterium zur Entscheidung der Kardinalfrage: Handelt es sich um eine Zellform oder um ein Detrituspartikel? 


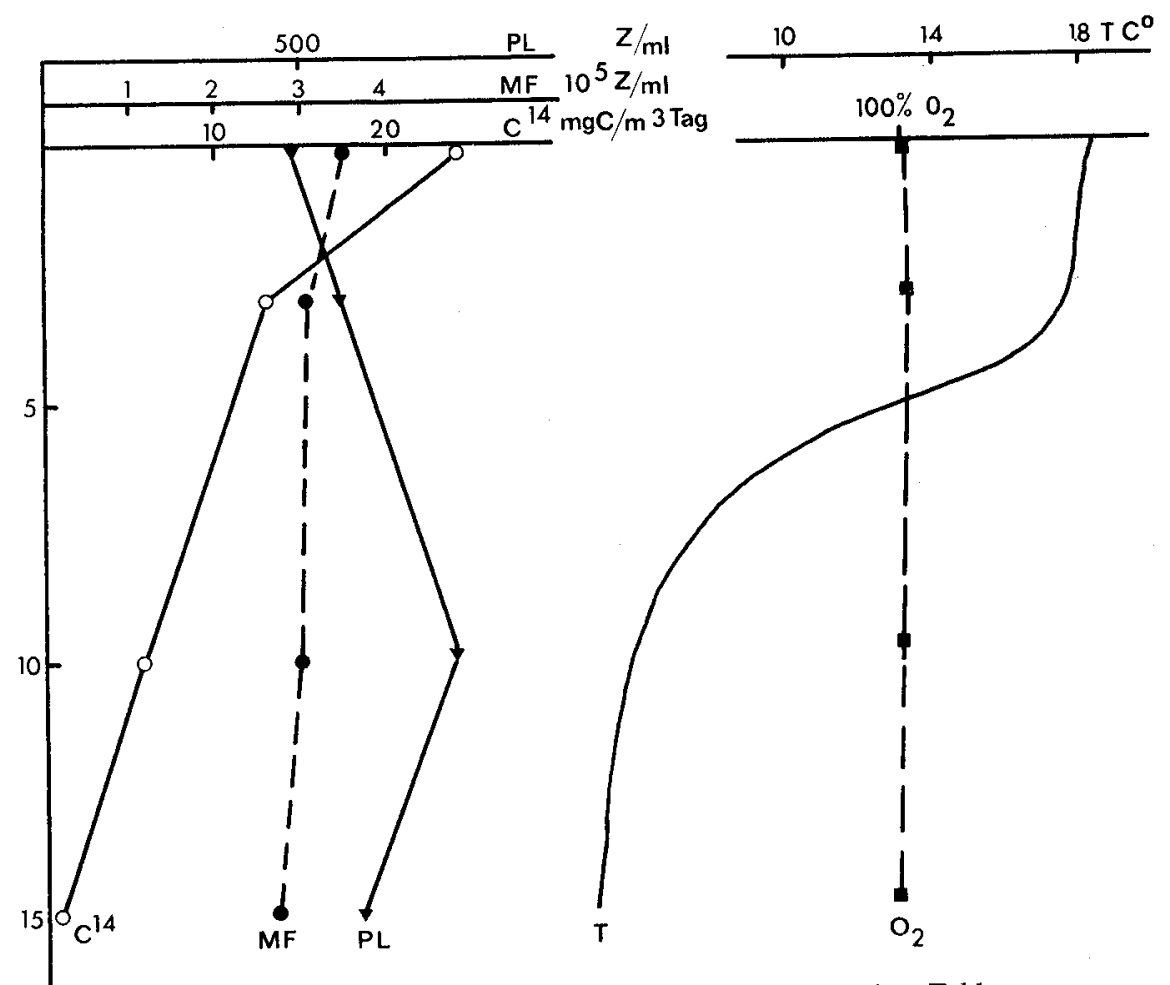

Abb. 10. Vertikalprofil vom 25. Juni 1968 aus dem Feldsee.

C14 Primärproduktion in $\mathrm{mg} \mathrm{C} / \mathrm{m}^{3} \mathrm{Tag}$,

MF auf Membranfiltern bestimmte Bakterien in $10^{5}$ Zellen $/ \mathrm{ml}$,

PL nach der Plattenmethode bestimmte Bakterien in Zellen/ml,

$\mathrm{O}_{2}$ Sauerstoffgehalt in \% Sättigung,

$\mathrm{T}$ Temperatur in $\mathrm{C}^{\circ}$.

Zur genauen Abklärung wurden fragliche Partikel auch mit 2500facher [ $25 \times 100]$ Vergrösserung kontrolliert. Je nach Zelldichte wurden 10 bis 100 Blickfelder ausgezählt. Die Berechnung der Anzahl Bakterien pro $\mathrm{ml}$ wurde nach KusNezow [22] durchgeführt.

\subsection{Resultate und deren Interpretation}

Als erstes Beispiel (Abb. 10) sei ein Vertikalprofil aus dem Feldsee vom 25. Juni 1968 angeführt.

Dieser oligotrophe [5] Schwarzwaldsee zeigte an unserem Untersuchungstag eine scharfe Sprungschicht. Die Primärproduktion ist mit einem Maximum von $24 \mathrm{mg} \mathrm{C/}$ $\mathrm{m}^{3}$ Tag auch für einen oligotrophen See recht gering [15]. Innerhalb der trophogenen Schicht lässt sich bei den Membranfilterbakterien keine ausgeprägte Schichtung feststellen, während die Plattenzahlen in $10 \mathrm{~m}$ Tiefe ein Maximum aufweisen, dessen Genese möglicherweise auf die bessere Adaptation der Keime auf das Plattenmedium zurückzuführen ist. Der Wert der Sauerstoffsättigung liegt über das ganze Profil bei $100 \%$.

Bei diesem oligotrophen See lassen sich aus einer Untersuchung keine direkten Schlüsse auf den Stoffumsatz in der trophogenen Schicht ziehen. Wahrscheinlich sind 
die Substratkonzentrationen so gering, dass sich keine Schichten ausgesprochen hoher bakterieller Tätigkeit mit entsprechender Populationsdichte herausbilden.

Der Vierwaldstättersee, Stelle vor dem Laboratorium Kastanienbaum (Tiefe $35 \mathrm{~m}$ ), wurde am 25. Mai $1968 \mathrm{zu}$ Beginn der Sommerstagnation untersucht (Abb. 11). Die Sprungschicht lag bei etwa $8 \mathrm{~m}$ Tiefe. Die Auswertung beschränkt sich auch hier auf den Bereich der trophogenen Schicht, weil sich hier, wie sich schon früher gezeigt hat [13], wesentliche Zusammenhänge zwischen Produktion und Destruktion erkennen lassen.

Unser Beispiel zeigt einen geschichteten See, dessen Plankton in einer starken Produktionsphase steht. An dieser Stelle des Vierwaldstättersees sind Primärproduktionen von $18 \mathrm{mg} \mathrm{C} / \mathrm{m}^{3} \mathrm{~h}$ schon recht hoch [23, 13].

Aus der Darstellung links in Abb. 11 geht hervor, dass in 2,5 m Tiefe sowohl bezüglich Primärproduktion als auch der Bakterienzahlen die höchsten Werte zu finden sind. Offenbar greifen hier Produktion und Destruktion recht eng ineinander, d.h. dass hier für die Bakterien substratmässig die optimalen Verhältnisse vorliegen. Wie sich diese Substratverhältnisse herausbilden, wird stark vom physiologischen Zustand der Algenpopulation abhängen [3].

Aus der Jahreszeit und der hohen Primärproduktion ist zu schliessen, dass ein grosser Teil in einem "physiologisch jungen" Zustand ist, oder, wie SOEDER [24] dies formulierte, als «aktive Organismen» vorliegen. Dabei wird die Zuwachsrate sicher wesentlich höher liegen als die Absterberate, so dass die Substratbildung durch Autolyseprodukte nicht in erster Linie für die Bakterienmaxima in der hauptproduktiven Schicht verantwortlich gemacht werden kann.

Von verschiedenen Algen ist die Abgabe von organischen Substanzen in das Kulturmedium bekannt [25]. So fand z.B. LEWIN [26] an Chlamydomonas mexicana, dass 25\% der Kohlenhydratproduktion der Alge laufend wieder ausgeschieden werden. WEINMANN [27] fand in eingehenden Untersuchungen an einer bakterienfreien Kultur von Scenedesmus quadricauda, dass keine gleichmässige Abgabe der organischen Stoffe in das Milieu erfolgt, dass vielmehr in der ersten Hälfte der logarithmischen Phase eine im Vergleich zur Algemasse sehr hohe Akkumulation von exkretierter organischer Substanz im Milieu auftritt.

Sicher dürfen diese In-vitro-Experimente nicht kritiklos auf das natürliche Milieu extrapoliert werden. Immerhin liegt die Vermutung nahe, dass eine "physiologisch junge» Phytoplanktonpopulation im natürlichen Milieu ähnliche Exkretionsverhältnisse aufweist. In unserem Beispiel ist es wahrscheinlich, dass zu dieser Untersuchungszeit die Exkretion der Phytoplanktonpopulation einen wesentlichen Einfluss auf die Substratkonzentration hatte und damit zur Bildung der Bakterienmaxima in der hauptproduktiven Schicht massgeblich beitrug.

Es erscheint uns wichtig, darauf hinzuweisen, dass neben diesen recht gut verständlichen und bezüglich der Dynamik des Stoffumsatzes ziemlich aussagekräftigen Feldbefunden auch schwer zu deutende Resultate auftraten.

Diese Erfahrung wurde am Bodensee-Überlingersee, Stelle Wasserfassung des Fernwasserwerkes der Stadt Stuttgart bei Sipplingen, am 17. August 1968 gemacht.

In Abb. 12 rechts, stellt man fest, dass die Temperaturschichtung mit einem geringen Sprung bei $9 \mathrm{~m}$ Tiefe wenig stabil ist. Ebenso zeigt die Phytoplanktonmenge und -artenverteilung bis in diese Tiefe geringe Unterschiede. Die hauptsächlichsten 

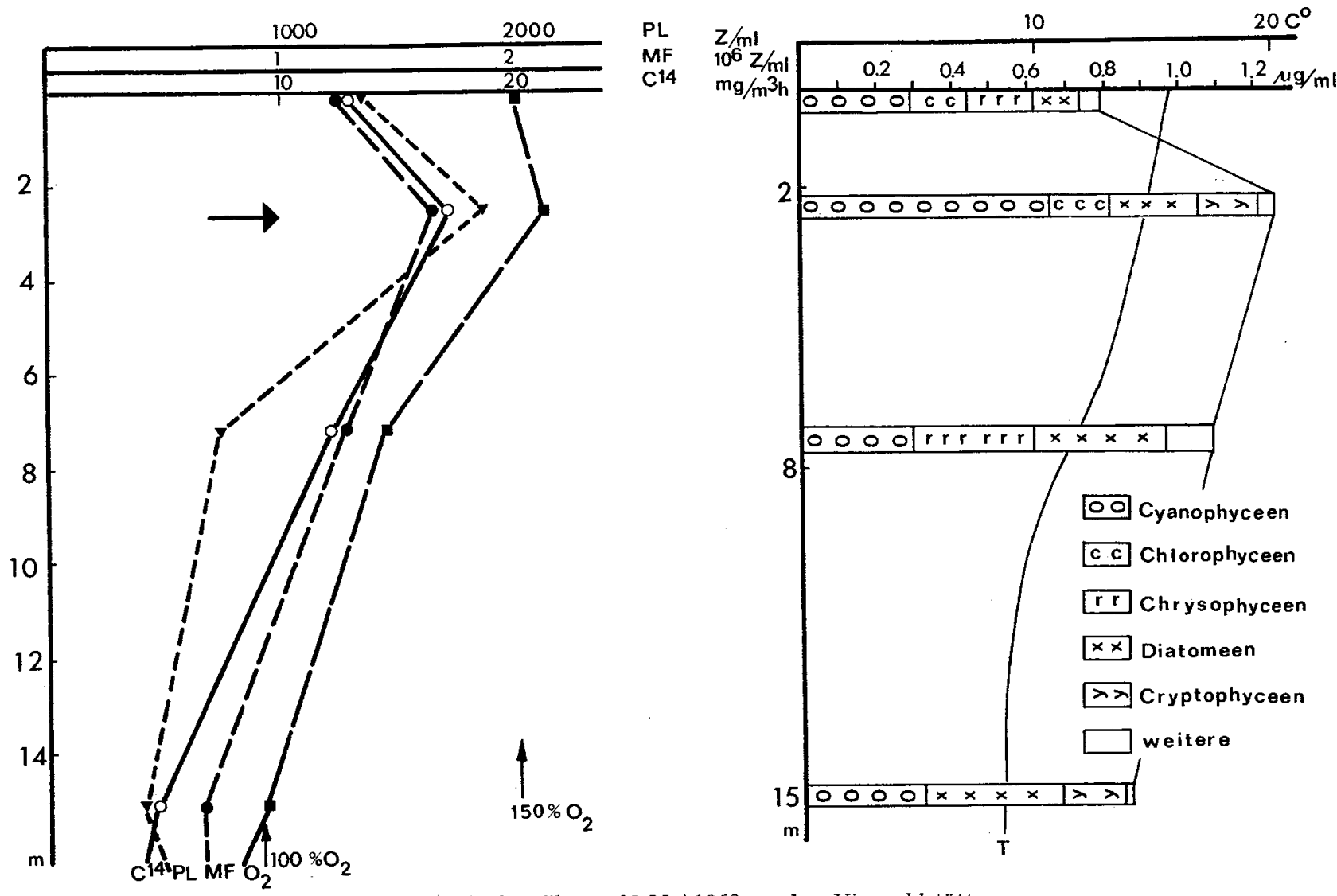

Abb. 11. Vertikalprofil vom 25. Mai 1968 aus dem Vierwaldstättersee.

Abb. links: $\mathrm{C}^{14}$ Primärproduktion in $\mathrm{mg} \mathrm{C} / \mathrm{m}^{3} \mathrm{~h}$,

MF auf Membranfiltern bestimmte Bakterien in $10^{6} \mathrm{Zellen} / \mathrm{ml}$,

PL nach der Plattenmethode bestimmte Bakterien in Zellen/ml,

Abb. rechts: Phytoplanktongehalt in $\mu \mathrm{g} / \mathrm{ml}$,

$\mathrm{O}_{2}$ Sauerstoffgehalt in \% Sättigung. 

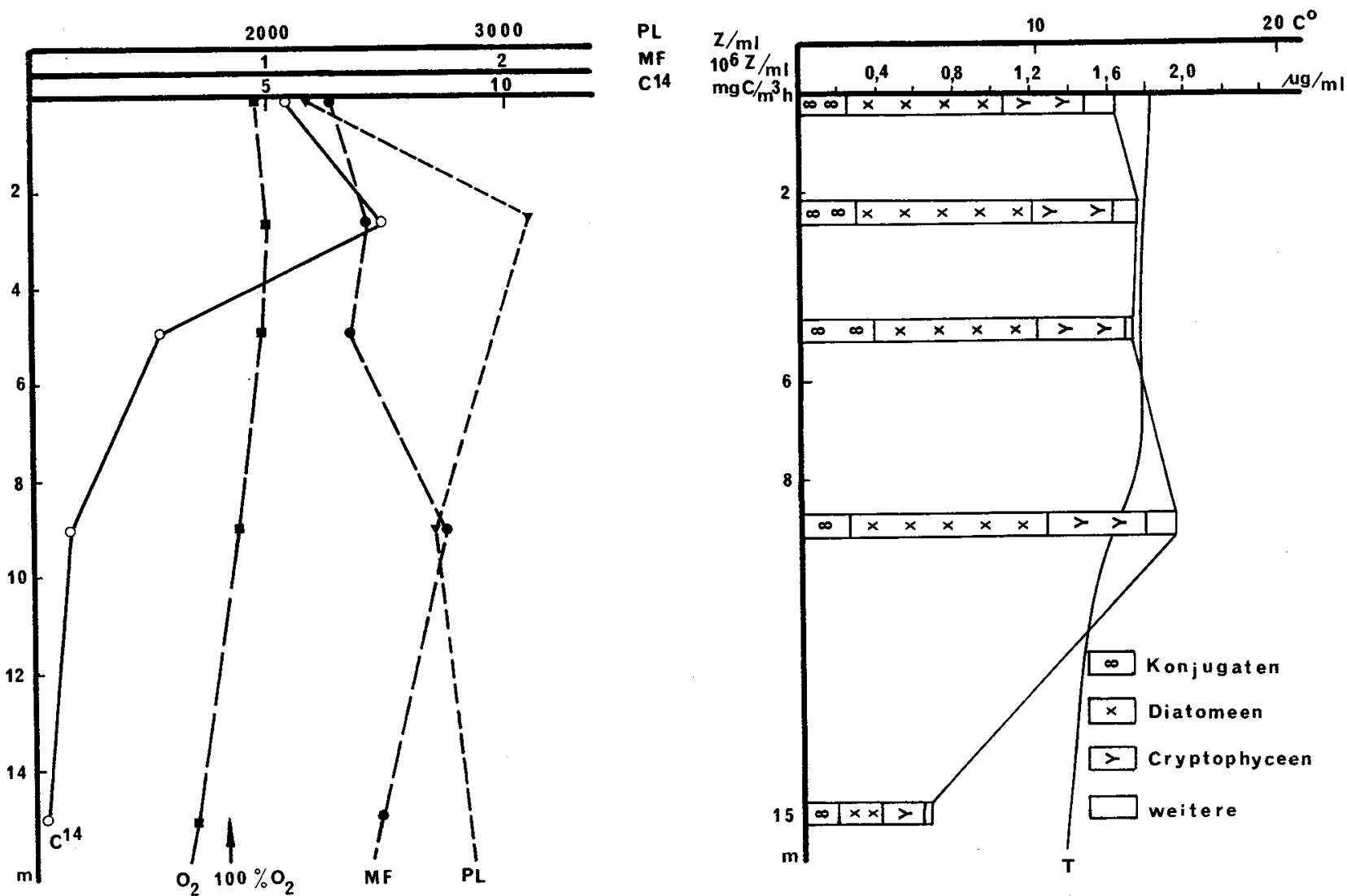

Abb.12. Vertikalprofil aus dem Bodensee-Überlingersee vom 17. August 1968. Erläuterungen s. Abb. 11. 


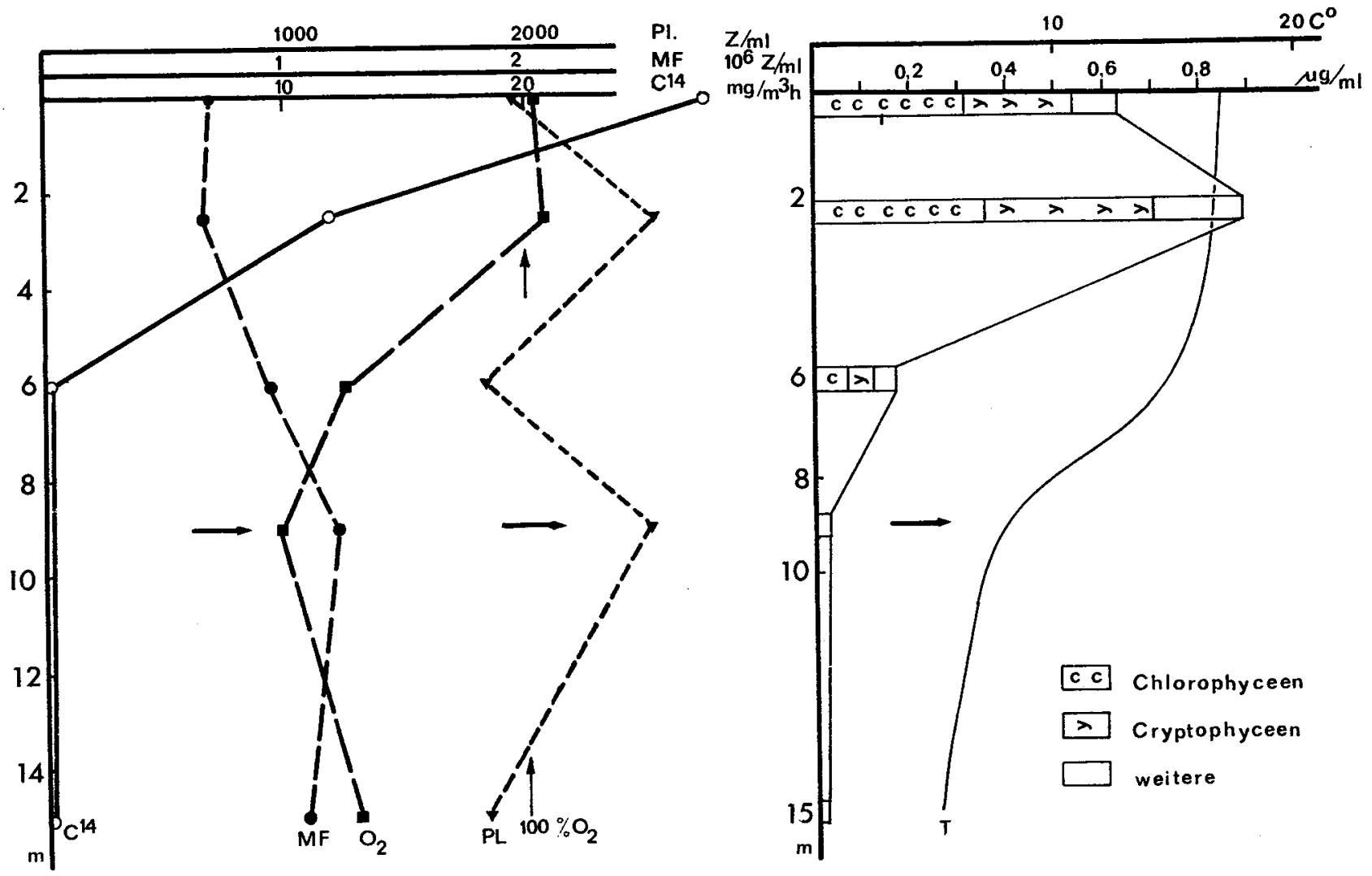

Abb.13. Vertikalprofil aus dem Titisee vom 12. September 1968. Erläuterungen s. Abb.11. 
Formen waren: bei den Konjugaten Mougeotia sp., bei den Diatomeen Fragilaria crotonensis, bei den Cryptophyceen, Rhodomonas und Cryptomonas.

Aus dem Verlauf der Bakterienkurven lässt sich nicht viel aussagen, mit Ausnahme des Maximums, das die Plattenzahlen in $2,5 \mathrm{~m}$, dem Primärproduktionsmaximum, aufweisen. Dies lässt sich möglicherweise so erklären, dass hier eine auf die hohe Nährstoffkonzentration der Platten besser adaptierte Population vorherrschte. Insofern ist dies verständlich, weil in der Schicht der höchsten Primärproduktion mehr leichter resorbierbare organische Substanzen vorhanden sind und damit ein grösserer Teil der latent vorhandenen Kümmerformen (zymogene Keime, JANNASCH [8] zu wachstumsfähigen Keimen heranwächst.

Die Schwierigkeit in der Interpretation dieses Profils dürfte darin zu suchen sein, dass wahrscheinlich infolge der wenig stabilen Schichtung schon verschiedene Umlagerungen stattgefunden haben.

Aus der nächsten Darstellung (Abb. 13) ist ersichtlich, dass im Titisee am 12. September 1968 die Hauptmasse der Bakterien eindeutig unterhalb der noch Plankton enthaltenden Schichten liegt.

Die Substratbildung für die Bakterien durch das Phytoplankton hat sich hier offenbar gegen die Autolyse und langsame Sedimentation verschoben. Es dürften hier prinzipiell andere Nährstoffquellen und eine andere Zusammensetzung der organischen Stoffe vorliegen als im Falle des angeführten Beispiels Vierwaldstättersee. Die Exkretionsvorgänge dürften hier nur noch eine geringe Rolle spielen, während durch Autolyse grössere Mengen organischen Substrats frei werden.

Die Vermutung, dass in diesen Verhältnissen die grosse bakterielle Aktivität der Mineralisierung im Metalimnion unterhalb der noch lebendes Plankton führenden Schicht liegt, wird in dieser Zone durch die eindeutig festgestellte Sauerstoffzehrung (Minimum von 49\% Sättigung) bestätigt. Interessant erscheint, dass auch in dieser "Spätsituation» in 2,5 m, d.h. in der photosynthetisch noch aktiven Schicht, ein relatives Plattenmaximum auftritt. Dieses Ergebnis dürfte auf dieselben Ursachen zurückzuführen sein, wie sie beim entsprechenden Maximum aus der Untersuchung vom Bodensee-Überlingersee diskutiert wurden.

Das räumliche Auseinanderweichen der Phytoplankton- und Bakterienschichten kann nach Overbeck [28] dazu führen, dass ohne Phytoplankton- und Primärproduktionsmaximum hohe Bakterienzahlen angetroffen werden, z.B. unmittelbar nach einer absterbenden Wasserblüte.

Es handelt sich hier um eine autolytische Phase, in der die extrazelluläre organische Substanz schneller zunimmt als die neu produzierte Algenmasse.

Diese Interpretationen der wenigen Einzelprofile sollen als Diskussionsbasis verstanden werden, da sie vor allem im Hinblick auf die dynamischen Vorgänge noch abgesichert werden müssen. Eine entsprechend ausgedehnte Untersuchung ist in Vorbereitung.

\section{Zusammenfassende Diskussion}

Die vorangehend geschilderte Situation im Titisee weckt die Frage nach der Verteilung der Bakterienarten: Welche Keimarten leben bevorzugt von den Algenexkreten? Welche Keimgruppen sind vorwiegend am Abbau der autolysierten Algenzellen beteiligt? Es ergeben sich hier Ansatzpunkte für die Laboratoriumsdiagnostik, 
die bei der Frage nach den draussen im See ablaufenden Abbauvorgängen allein weiterhelfen kann.

Es erwies sich, dass eine repräsentative Erfassung des Keimspektrums der Seen mit einem auch in der $p H$-Einstellung normierten "Standardagar» unmöglich ist. Vergleichbare Aussagen lassen sich für die verschiedenen Seen erst dann treffen, wenn spezifisch auf den jeweiligen See eingestellte Nährböden eingesetzt werden.

Diese Erfahrung bestätigt aufs neue, dass nur die Parallelbeobachtung der verschiedenen physikalisch-chemischen und biologischen Vorgänge unter Einsatz einer differenzierten Untersuchungstechnik die Aussicht auf Erfolg bei der bilanzmässigen Erfassung von Stoffumsätzen in den Gewässern eröffnet.

In diesem Zusammenhang sei noch eine prinzipielle Bemerkung zu den Methoden der bakteriologischen Untersuchung der Gewässer angebracht:

Jede Methode wird verschiedene Bakterienzahlen ergeben, ebenso werden schon kleine Modifikationen das Verhalten der Population verändern. Es gibt demnach keine absolut "richtigen» Zahlen, sondern relative und untereinander vergleichbare und aussagekräftige Resultate bezüglich der angewandten Methode.

Aus dieser Sicht muss auch die bekannte Differenz zwischen den Bakterienzahlen nach der Membranfiltermethode und der Plattenmethode gesehen werden. In unseren Untersuchungen lagen die Membranfilterzahlen um einen Faktor von $10^{2}$ bis $10^{3}$ höher als die Plattenzahlen. Dies ist eine bekannte Tatsache (KusNEzow [21]), auf deren Ursachen in diesem Zusammenhang nicht eingegangen werden soll. Bermerkenswert ist, dass diese Verhältniszahl in Zonen, die hohe auf Platten ermittelte Bakterienzahlen aufweisen, kleiner war. Zum Beispiel betrug sie im Vierwaldstättersee bei $2,5 \mathrm{~m}$ Tiefe $0,9 \cdot 10^{3}$ gegenüber einem Durchschnitt über das ganze Profil von $1,2 \cdot 10^{3}$; dies lässt den Schluss zu, dass bei höherer Konzentration organischen Substrates auch mehr Keime auftreten, die das relativ hohe Nährstoffangebot der Agarplatten tolerieren.

Welch entscheidende Rolle die Probleme der Adaptation bei bakteriologischen Untersuchungen spielen, haben die Untersuchungen im ersten Teil der Arbeit deutlich gezeigt.

Als Ergebnis kann festgehalten werden:

1. Bei den vorliegenden Vergleichsuntersuchungen liess sich gelegentlich ein $\mathrm{Zu}$ sammenfallen der Keimzahlmaxima nach der Membranfiltermethode und der Plattenmethode feststellen.

2. Berücksichtigt man die Ergebnisse der gleichzeitigen Sauerstoff-, Plankton- und Primärproduktionsuntersuchungen, dann kann dieser Befund darauf zurückgeführt werden, dass in Zonen mit hoher Konzentration organischen Materials (sei es aus Exkretion oder Autolyse) die Anzahl physiologisch aktiver, an das höhere Nährstoffangebot der Agarplatten angepasster Bakterien stets zunimmt.

3. Diese Erscheinung macht es wahrscheinlich, dass vom angebotenen Substrat eine von Fall zu Fall unterschiedliche Selektionswirkung auf die latent vorhandenen Bakterien ausgeübt wird und sich eine Population ausbildet, die den gegebenen Nährstoffbedingungen am besten angepasst ist.

4. In beschränktem Umfang ist möglich, schon aus wenigen bakteriologischen Momentuntersuchungen, bei welchen die wichtigsten Umweltparameter berücksichtigt werden, Rückschlüsse auf die Dynamik des Stoffumsatzes in den Gewässern zu ziehen. 


\section{Zusammenfassung}

1. An einigen Seen des Schwarzwaldes und der Schweiz wurden 1968 limnobakteriologische Untersuchungen durchgeführt.

2. Bei Profilaufnahmen mit der Plattenmethode wurde das $\mathrm{pH}$ des Agars variiert. Die pH-Werte der Platten mit den höchsten Koloniezahlen liegen mit einer Ausnahme nahe bei den aktuellen $\mathrm{pH}$-Werten der Gewässer.

3. Die dabei erhaltenen Plattenzahlen weisen auf Schichtungen artverschiedener Bakterien hin.

4. Die Abhängigkeit der Bakterienpopulation von der vorhandenen organischen Substanz wurde durch Erfassung der Parameter Temperatur, Sauerstoffgehalt, pH-Wert, Phytoplanktongehalt und Primärproduktion aufgezeigt. Produktion und Destruktion greifen recht eng ineinander und lassen zu verschiedenen Jahreszeiten typische Zusammenhänge erkennen.

\section{SUMMARY}

In 1968, limnobacteriological investigations were carried out in some lakes of the Black Forest and of Switzerland, applying direct microscopic count and a differentiated plate-count-method. Samples were taken from different depths of the profile, and the $\mathrm{pH}$ value of the incubation substrate was varied.

The colony maxima were found on agar with low $\mathrm{pH}$, whenever the samples were taken from comparatively acidic waters on the one hand, and, on the other hand, colony maxima were encountered when samples of more alcaline waters were spread on the agar medium with a somewhat higher $\mathrm{pH}$ (Fig. 8). The maxima and the minima in the vertical distribution of germs on the plates with $\mathrm{pH}$ values varying only by $0.5 \mathrm{pH}$ units revealed that the mass of bacteria in vertical stratifications often has entirely different physiological demands. This means that we are dealing with stratifications of different species of bacteria that can be selected by mere variation of the $\mathrm{pH}$ of the incubation substrate (Fig. 2, 4 and 5).

At the same time, the ecological relationship between the bacteria and some parameters that influence their growth (temperature, oxygen content, $\mathrm{pH}$ value, primary production and phytoplankton content) was investigated.

It was then found that there is a limited possibility to draw some conclusions concerning the dynamics of metabolism in the lake from these few profile samples. In a spring situation (Fig. 11), it was found that the processes of production and of destruction are closely interlinked, and it was presumed that this phenomenon is due to a higher degree of excretion from the "physiologically young" plankton population. In an autumn investigation, a considerable distance was found between a very reduced productive layer and the zone of higher bacterial activity.

Other profiles have been found, which were more difficult to interpret (Fig.10 and 12).

Furthermore, different aspects of bacteriological investigation of waters are discussed.

\section{LITERATURVERZEICHNIS}

[1] Babenzien H.D., Probleme und Aufgaben der Hydrobakteriologie, Limnologica 1, 1, 45 (1962).

[2] RoDHE W., Dynamik des limnischen Stoff- und Energiehaushaltes, Verh. Internat. Verein. Limnol. 14, 300 (1961).

[3] Overbeck J., Bakterien im Gewässer, Umschau 19, 68, 587 (1968).

[4] LeEmann W., Der Vievwaldstättersee (Rentsch-Verlag, Zürich, 1949).

[5] Elster H.-J. und Motsch B., Untersuchungen iiber das Phytoplankton und die organische Uvproduktion in einigen Seen des Hochschwarzwaldes, im Schleinsee und Bodensee, Arch. Hydrobiol./Suppl. XXXVIII 4, 291 (1966). 
[6] ELster H.-J., Untersuchungen über den limnochemischen Stoffwechsel der Hochschwarzwaldseen, Ber. Naturf. Ges., Freiburg i. Br. 51, 149 (1961).

[7] Ruschke R. und KÖHN K., "Keimzahlbestimmungen" aus Wasserproben nach der Plattenmethode bei besonderer Berücksichtigung des $p H$-Wertes der verwendeten Nährböden, $Z$. Bakteriol. II. Abt. 124, Heft 1 (1970).

[8] JanNasch W.H., Zur Ökologie der zymogenen planktischen Bakterienflora natürlicher Geqüsser, Arch. Mikrobiol. 23, 146 (1955).

[9] Selenka F. und Ruschke R., Keimzahlen und Fäkalindikatoren im Bodenseewasser, Arch. Hyg. Bakt. 14, 273-287.

[10] Ruschke R. und RATH M., Sporocytophaga cauliformis Knorr und Gräf, eine Myxobakterienart mit grosser Bedeutung für den Abbau organischen Materials, Arch. Hydrobiol./Suppl. XXVIII, 377 (1965).

[11] GräF W. und StürzenhoFecker P., Dev Myxobakterientypenquotient als Eutrophierungsindikator bei Oberflächengewässern, Arch. Hyg. 149, 265 (1965).

[12] Schulle, Qualitative und quantitative Untersuchungen über das Phytoplankton des Titisees im jahreszeitlichen Verlauf sowie einige Bemerkungen zum derzeitigen Zustand des Sees. Arch. Hydrobiol., Suppl. Fachanschriften, (1970) im Druck.

[13] SCHEGG E., Beziehungen zwischen Planktonentwicklung und Bakterien im Vievwaldstättersee und Rotsee, Schweiz. Z. Hydrol. 30, 2, 289 (1968).

[14] Kusnezow S. J., und Romanenke W. I., Produktion der Biomasse heterotropher Bakterien und die Geschwindigkeit ihrev Vermehrung im Rybinsk-Stausee, Verh. int. Ver. Limnol. 16, 3, 1493 (1966).

[15] VOLLENWEIDER R., Die wissenschaftlichen Grundlagen der Seen- und Fliessgewässereutrophierung, OECD-Bericht, DAS/CSI/68.27 (1968).

16] OHLE, W., Typologische Kennzeichnung dev Gewässer auf Grund ihver Bioaktivität, Verh. int. Ver. Limnol. 13, 196 (1958).

[17] Nauwerck A., Die Beziehungen zwischen Zooplankton und Phytoplankton im See Erken, Symb. bot. upsal. 77, 5 (1963).

[18] Амвӥнц. H., Die praktische Anwendung der elektrochemischen Sauerstoffbestimmung im Wasser, Schweiz. Z. Hydrol. 22, 23 (1960).

[19] UTERMÖHL H., Zuv Vevollkommnung dev quantitativen Phytoplanktonmethodik, Mitt. int. Ver. Limnol. $I X, 1$ (1958).

[20] Pavoni M., Die Bedeutung des Nannoplanktons im Vergleich zum Netzplankton, Schweiz. Z. Hydrol. 25, 2, 219 (1963).

[21] Steeman-Nielsen E., The Use of Radio-Active Carbon $\left({ }^{14} C\right)$ for Measuring of Organic Production in the Sea, J. du Cons. 18, 117 (1952).

[22] Kusnezow S. J., Die Rolle der Mikroorganismen im Stoffkreislauf der Seen, DVW, Berlin (1959).

[23] GÄchter R., Phosphorhaushalt und planktische Primärproduktion im Vievelaldstättersee, Schweiz. Z. Hydrol. 30, 1, 1 (1968).

[24] Soeder C., Some Aspects of Phytoplankton Growth and Activity, Mem. Ist. Ital. Idrobiol., 18 Suppl., 47 (1965).

[25] Moore B.G. and Tischler R.G., Extracellular Polysaccharides of Algae: Effects on LifeSupport Systems, Science (Washington) 745, 586 (1964).

[26] Lewin R. A., Extracellular Polysacchavides of Green Algae, Can J. Microbiol. 2, 665 (1956).

[27] WeINmann G., Gelöste Kohlenhydrate und andeve organische Stoffe in natüvlichen Gewässern und in Kulturen von Scenedesmus quadricauda, Diss. Universität Kiel (1968).

[28] Overbeck J., Prinzipielles zum Vorkommen der Bahterien im See, Mitt. Internat. Verein. Limnol. 14, 134 (1968).

Anschrift der Autoren :

Ernst Schegg, dipl. sc. nat. ETH, EAWAG, Ueberlandstrasse 133, CH-8600 Dübendorf; Dr. Rainer Ruschke, Betriebslaboratorium der Firma C.H. Knorr GmbH, D-71 Heilbronn.

Separatdruck aus der Schweiz. Zeitschrift für Hydrologie 32, Fasc. 1 (1970) Herausgegeben mit Unterstützung der Stiftung der Wirtschaft zur Förderung des Gewässerschutzes in der Schweiz 